Supporting information

\title{
Photodynamic inactivation of ESKAPE group bacterial pathogens in planktonic and biofilm cultures using metallated porphyrin-doped conjugated polymer nanoparticles
}

Sol R. Martínez ${ }^{\mathrm{a}, \mathrm{d}}$, Luis E. Ibarra ${ }^{\mathrm{b}, \mathrm{f}}$, Rodrigo A. Ponzio ${ }^{\mathrm{c}, \mathrm{d}}$, María V. Forcone ${ }^{\mathrm{c}}$, Ana B. Wendel ${ }^{\mathrm{c}}$, Carlos A. Chesta ${ }^{\mathrm{a}, \mathrm{d}}$, Mariana B. Spesia ${ }^{\mathrm{a}, \mathrm{e}}$, Rodrigo E. Palacios ${ }^{\mathrm{a}, \mathrm{d}} *$

${ }^{a}$ Departamento de Química, ${ }^{b}$ Departamento de Biología Molecular, ${ }^{c}$ Departamento de Física.

Facultad de Ciencias Exactas Fisicoquímicas y Naturales, Universidad Nacional de Río Cuarto, X5804BYA Río Cuarto, Córdoba, Argentina

${ }^{d}$ Instituto de Investigaciones en Tecnologías Energéticas y Materiales Avanzados (IITEMA), Universidad Nacional de Río Cuarto, Consejo Nacional de Investigaciones Científicas y Tecnológicas, X5804BYA Río Cuarto, Córdoba, Argentina.

e Instituto de Desarrollo Agroindustrial y de la Salud (IDAS), Universidad Nacional de Río Cuarto, Consejo Nacional de Investigaciones Científicas y Tecnológicas (CONICET), X5804BYA Río Cuarto, Córdoba, Argentina.

${ }^{f}$ Instituto de Biotecnología Ambiental y Salud (INBIAS) Universidad Nacional de Río Cuarto y Consejo Nacional de Investigaciones Científicas y Tecnológicas (CONICET), X5804BYA Río Cuarto, Córdoba, Argentina.

*Corresponding autor: Rodrigo E. Palacios E-mail address: $\underline{\text { rpalacios@exa.unrc.edu.ar }}$ 


\section{This section includes:}

\section{NUMBER OF CPN NEEDED TO FORM A MONOLAYER OVER EACH BACTERIA}

\section{SUPPORTING FIGURES}

Scheme S1. The conjugated polymer (F8BT), the amphiphilic polymer (PS-PEG-COOH) and the metallated porphyrin are non-covalently bound. Hydrophobic interactions between F8BT chains, polystyrene backbone of PS-PEG-COOH and PtOEP units produce densely packed CPNs in which F8BT and PtOEP are in close contact. Considering the excellent solubility of polyethylene oxide in water, most PEG-COOH side chains are expected to be extended toward the aqueous solution. ${ }^{1}$ Further, the CPNs suspended in growth medium showed excellent colloidal stability, no precipitates were observed even after several days. ${ }^{2}$

Figure S1. PDI treatment effect evaluated by measuring viable bacterial concentration as a function of irradiation time in planktonic cultures of reference strains of Gram-positive specie, $S$. aureus, panel A: MSSA 29213 and panel B: MRSA 43300. Bacterial suspensions + light + CPNs: $6.5 \mathrm{mg} / \mathrm{L}$ (dark orange square), $0.6 \mathrm{mg} / \mathrm{L}$ (orange triangle), $0.3 \mathrm{mg} / \mathrm{L}$ (light orange diamond) and $0.06 \mathrm{mg} / \mathrm{L}$ (light orange star). Bacterial control without CPNs (dark yellow sphere) and bacterial control with CPNs $(6.5 \mathrm{mg} / \mathrm{L}$ ) but without irradiation (grey sphere). Average irradiance (radiant flux density) $=16 \mathrm{~mW} / \mathrm{cm}^{2}$.

Figure S2. PDI treatment effect evaluated by measuring viable bacterial concentration as a function of irradiation time in planktonic cultures of methicillin-resistant clinical strains of $S$. aureus (panels show: A. MRSA 771; B. MRSA 773; C. MRSA 9453; D. MRSA 9455). Bacterial suspensions + light + CPNs: $6.5 \mathrm{mg} / \mathrm{L}$ (dark orange square) and $0.6 \mathrm{mg} / \mathrm{L}$ (orange triangle). Bacterial control without CPNs (dark yellow sphere) and bacterial control with CPNs $(6.5 \mathrm{mg} / \mathrm{L}$ ) but without irradiation (grey sphere). Average irradiance (radiant flux density) $=16 \mathrm{~mW} / \mathrm{cm}^{2}$.

Figure S3. PDI treatment effect evaluated by measuring viable bacterial concentration as a function of irradiation time in planktonic cultures of Gram-negative species, $K$. pneumoniae and E. coli. A, K. pneumoniae culture + CPNs: $6.5 \mathrm{mg} / \mathrm{L}$ (dark orange square); $0.6 \mathrm{mg} / \mathrm{L}$ (orange triangle). Bacterial control without CPNs (dark yellow sphere) and bacterial control with CPNs $(6.5 \mathrm{mg} / \mathrm{L}$ ) but without irradiation (grey sphere). B, E. coli + light + CPNs: $16.5 \mathrm{mg} / \mathrm{L}$ (brown circle). Bacterial control without CPNs (dark yellow sphere) and bacterial control with of CPNs 
$(16.5 \mathrm{mg} / \mathrm{L})$ but without irradiation (grey sphere). Average irradiance (radiant flux density) $=16$ $\mathrm{mW} / \mathrm{cm}^{2}$.

Figure S4 Flow cytometry results for CPNs and Bacteria interaction. FSC-A vs SSC-A dot plots $\left(10^{5}\right.$ total events converted to a dot density color scale) corresponding to: buffer media without bacteria (A, C) and with $10^{6} \mathrm{CFU} / \mathrm{mL}$ of E. coli (B) and S. aureus (D). The arbitrary gate region (black ellipsoid) chosen for each bacterial sample is also shown in the corresponding buffer control. The percentage values of total events within each gate region are shown next to it. FSCA $v s$. SSC-A dot plots and corresponding green channel $\left(\lambda_{\mathrm{ex}}=488 \mathrm{~nm} \lambda_{\mathrm{em}}=525-530 \mathrm{~nm}\right)$ fluorescence histograms of $0.1(\mathrm{E}) 1.0(\mathrm{~F})$ and $10.0(\mathrm{G}) \mathrm{mg} / \mathrm{L}$ CPNs dispersion in PBS.

Figure S5. Relative biofilm biomass quantification as determined by the $\mathrm{CV}$ staining assay. Panel A) shows the Gram-positive S. aureus strains biomass production after $24 \mathrm{~h}$ of biofilm formation. Panel B) shows the biofilm biomass quantification in Gram-negative samples.

Figure S6. Biofilm biomass and metabolic activity measured by CV (purple bars) and MTT (yellow bars) colorimetric assays, respectively. The violet box on the left displays the Grampositive $S$. aureus strains whereas the pink box on the right groups the Gram-negative $P$. aeruginosa, $K$. pneumoniae and $E$. coli. The plots show from left to right: bacteria + light; bacteria + light + CPNs ( 6.5 and $16.5 \mathrm{mg} / \mathrm{L})$; and in the case of negative species with a $35 \mathrm{mg} / \mathrm{L}$ of CPNs. Biofilms samples were exposed to a light dose of $57.6 \mathrm{~J} / \mathrm{cm}^{2}\left(16 \mathrm{~mW} / \mathrm{cm}^{2}\right.$ for $\left.60 \mathrm{~min}\right)$.

Figure S7. Biofilm biomass and metabolic activity measured by CV (purple bars) and MTT (yellow bars) colorimetric assays, respectively. The violet box on the left displays the Grampositive $S$. aureus strains whereas the pink box on the right groups the Gram-negative $P$. aeruginosa, $K$. pneumoniae and $E$. coli. The plots show from left to right: bacteria; bacteria CPNs ( 6.5 and $16.5 \mathrm{mg} / \mathrm{L}$ ); and in the case of negative species with a $35 \mathrm{mg} / \mathrm{L}$ of CPNs.

\section{SUPPORTING REFERENCES}




\section{NUMBER OF CPN NEEDED TO FORM A MONOLAYER OVER EACH BACTERIA}

\section{Coccus}

The total surface of a coccus bacteria of radius $R$ is $S_{c}=4 \pi R^{2}$. Assuming $r \ll R$, where $r$ is the NPCs radius, the maximum number of nanoparticles $\left(N_{c}\right)$ that fit on the bacteria's surface can be obtained considering a two dimensional packing of circles of surface $S_{n p}=\pi r^{2}$ in the surface $S_{c}$ :

$$
N_{c}=\frac{S_{c}}{S_{n p}} \eta
$$

where $\eta$ is the packing density. The highest density packing possible is the hexagonal packing $\eta=$ $\frac{\pi \sqrt{3}}{6} 3$, which yields:

$$
N_{c}=\frac{2 \pi(R)^{2}}{\sqrt{3} r^{2}}
$$

For $r=14 \mathrm{~nm}^{2}$ and $R=500 \mathrm{~nm},{ }^{4} N_{c} \approx 1300$. At the lower CNP concentration used in experiments shown in Figure 3, i.e. $0.1 \mathrm{mg} / \mathrm{L}, \mathrm{CNP}$ concentration is around $2 \times 10^{-11} \mathrm{M} .{ }^{5}$ On the other hand, the concentration of bacteria is $1 \times 10^{6}$ per $\mathrm{cm}^{3}$ is $1.7 \times 10^{-15} \mathrm{M}$. Hence, it can be calculated that there is about $12000 \mathrm{CNP}$ per bacterium, which is more than 10 times of $N_{c}$. From this simple estimation we concluded than in the cytometry experiments the number of CNP largely exceeds the concentration required to fully covert the bacteria surface, even assuming a very compact packing model as the considered here.

\section{Bacillus}

A bacillus surface $S_{b}$ can be approximated by a cylinder of radius $R$ and length $d$, with its both planar sides replaced by two semi-spheres of radius $R$ :

$$
S_{b}=4 \pi R^{2}+2 \pi R d
$$

Again, the maximum number of nanoparticles per bacteria $N_{b}$ is:

$$
N_{b}=\frac{S_{b}}{S_{n p}} \eta
$$

Which, assuming the same hexagonal packing, in this case yields: 


$$
N_{b}=\frac{\pi \sqrt{3}\left(4 R^{2}+2 R d\right)}{6 r^{2}}
$$

For $r=14 \mathrm{~nm}, R=250 \mathrm{~nm}$ and $d=1500 \mathrm{~nm} N_{b} \approx 4500 .{ }^{6}$ Following a similar reasoning to the one previously made for the coccus case, it can be concluded that even at the lower concentrations of CNP used in cytometric experiments, particles concentration always exceeds that required to completely cover the bacteria surface. 


\section{SUPPORTING FIGURES}
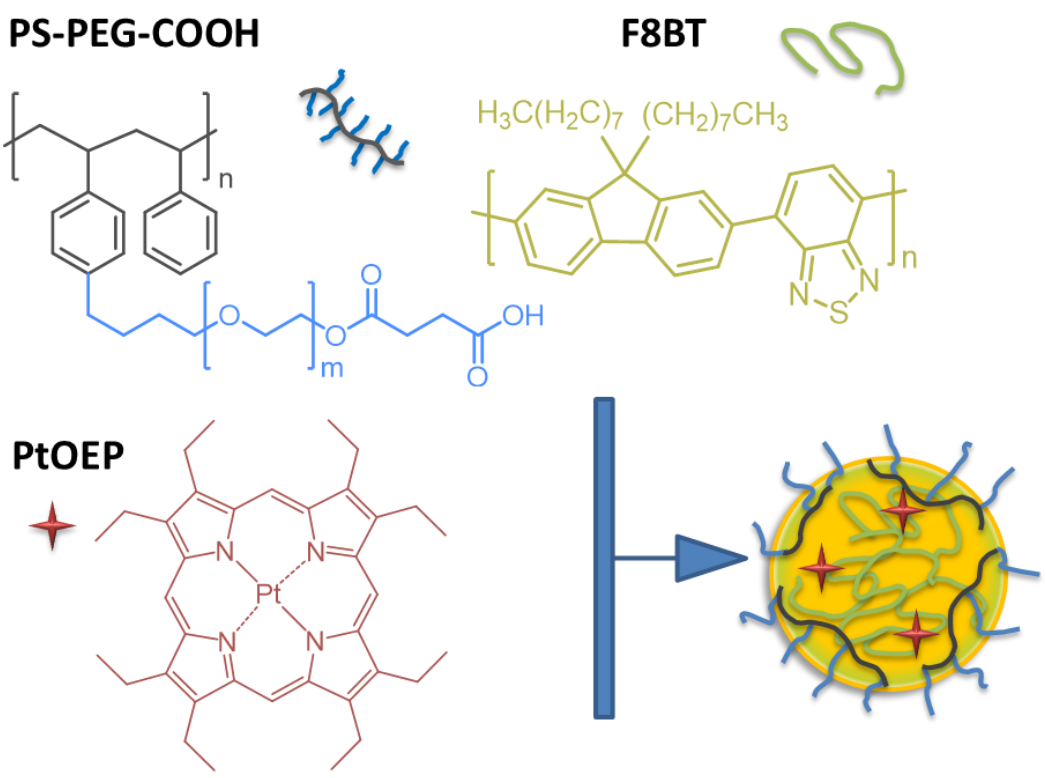

Scheme S1. The conjugated polymer (F8BT), the amphiphilic polymer (PS-PEG-COOH) and the metallated porphyrin are non-covalently bound. Hydrophobic interactions between F8BT chains, polystyrene backbone of PS-PEG-COOH and PtOEP units produce densely packed CPNs in which F8BT and PtOEP are in close contact. Considering the excellent solubility of polyethylene oxide in water, most PEG-COOH side chains are expected to be extended toward the aqueous solution. ${ }^{1}$ Further, the CPNs suspended in growth medium showed excellent colloidal stability, no

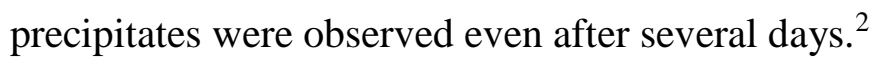




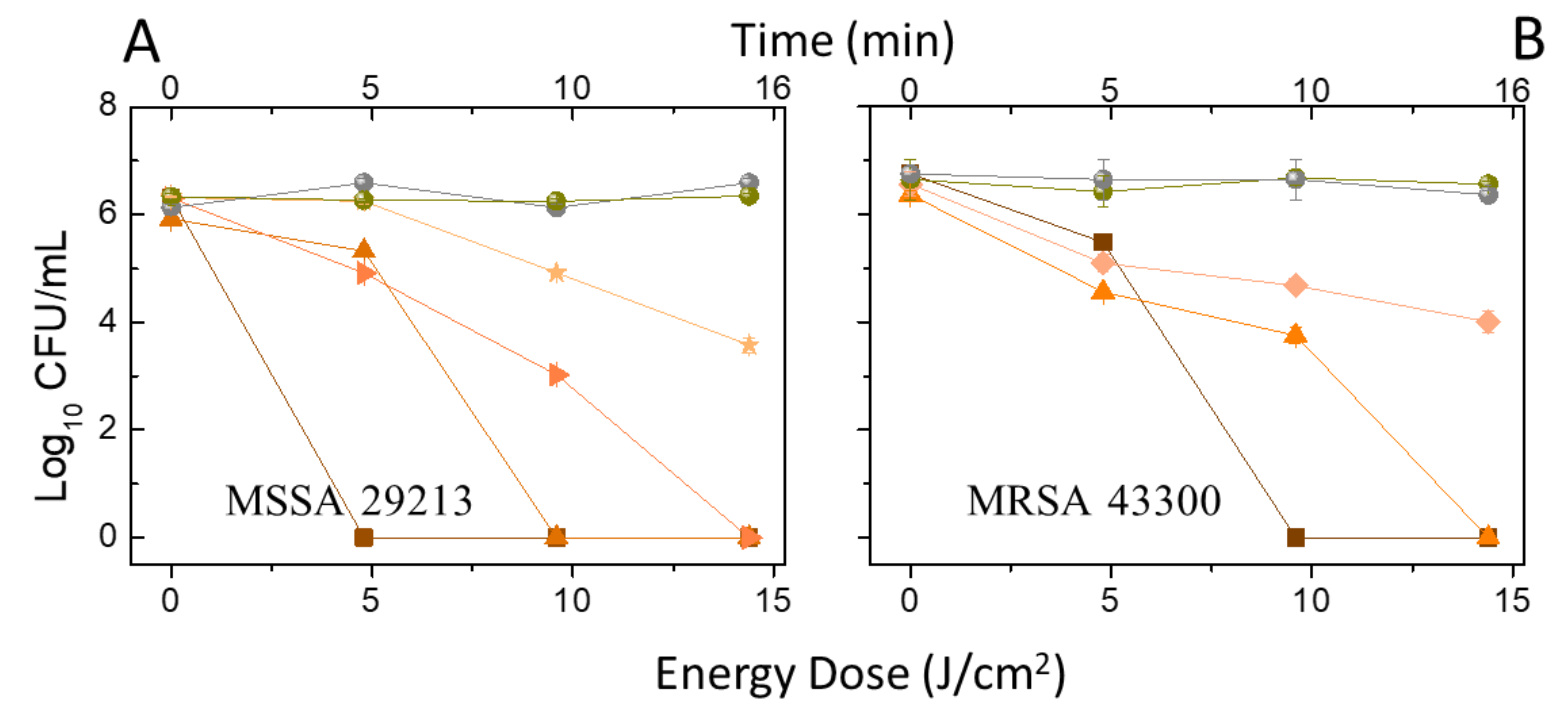

Figure S1. PDI treatment effect evaluated by measuring viable bacterial concentration as a function of irradiation time in plancktonic cultures of reference strains of Gram-positive specie, $S$. aureus, panel A: MSSA 29213 and panel B: MRSA 43300. Bacterial suspensions + light + CPNs: $6.5 \mathrm{mg} / \mathrm{L}$ (dark orange square), $0.6 \mathrm{mg} / \mathrm{L}$ (orange triangle), $0.3 \mathrm{mg} / \mathrm{L}$ (light orange diamond) and $0.06 \mathrm{mg} / \mathrm{L}$ (light orange star). Bacterial control without CPNs (dark yellow sphere) and bacterial control with CPNs $(6.5 \mathrm{mg} / \mathrm{L}$ ) but without irradiation (grey sphere). Average irradiance (radiant flux density) $=16 \mathrm{~mW} / \mathrm{cm}^{2}$. 

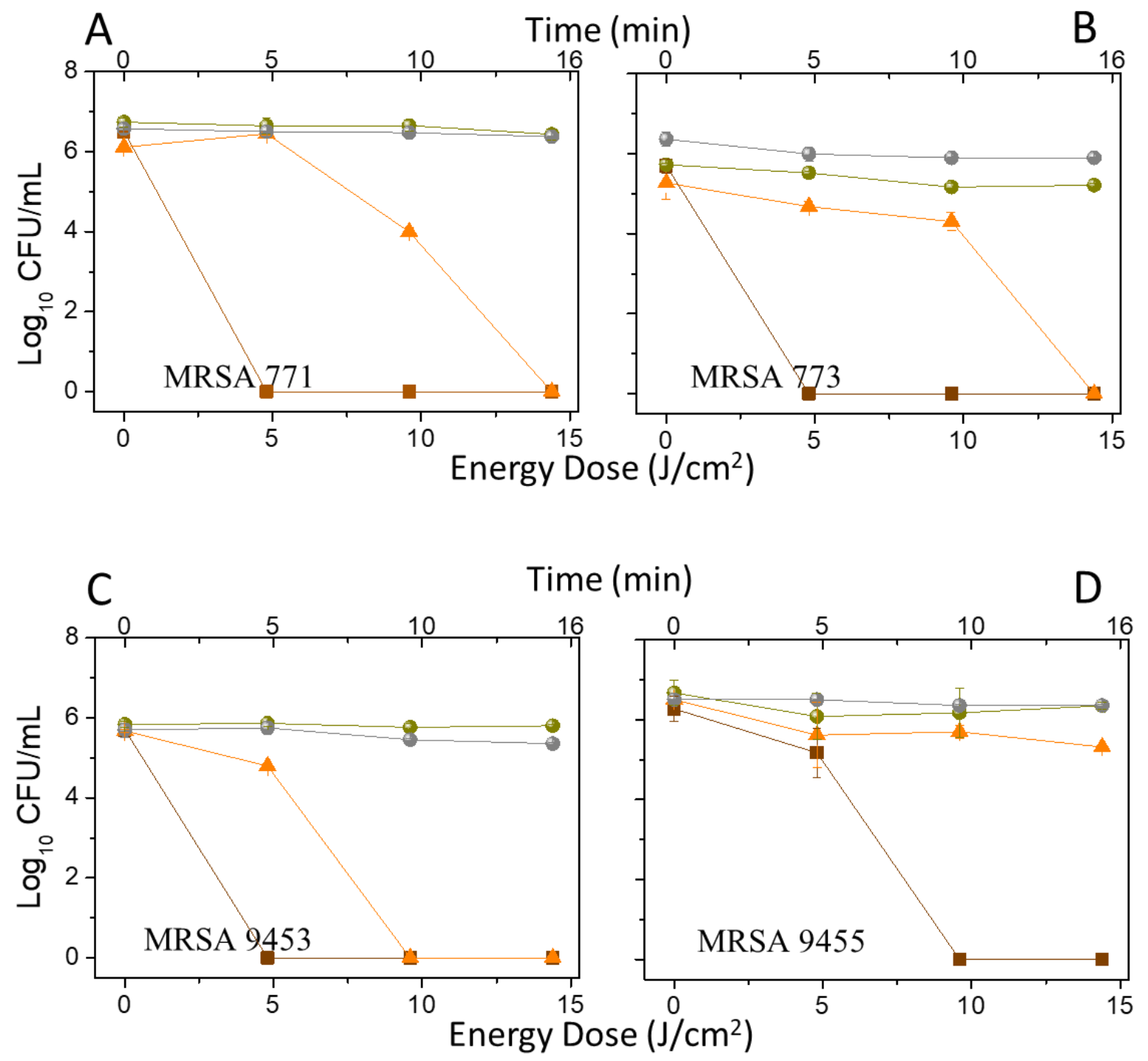

Figure S2. PDI treatment effect evaluated by measuring viable bacterial concentration as a function of irradiation time in planktonic cultures of methicillin-resistant clinical strains of $S$. aureus (panels show: A. MRSA 771; B. MRSA 773; C. MRSA 9453; D. MRSA 9455). Bacterial suspensions + light + CPNs: $6.5 \mathrm{mg} / \mathrm{L}$ (dark orange square) and $0.6 \mathrm{mg} / \mathrm{L}$ (orange triangle). Bacterial control without CPNs (dark yellow sphere) and bacterial control with CPNs (6.5 mg/L) but without irradiation (grey sphere). Average irradiance (radiant flux density) $=16 \mathrm{~mW} / \mathrm{cm}^{2}$. 


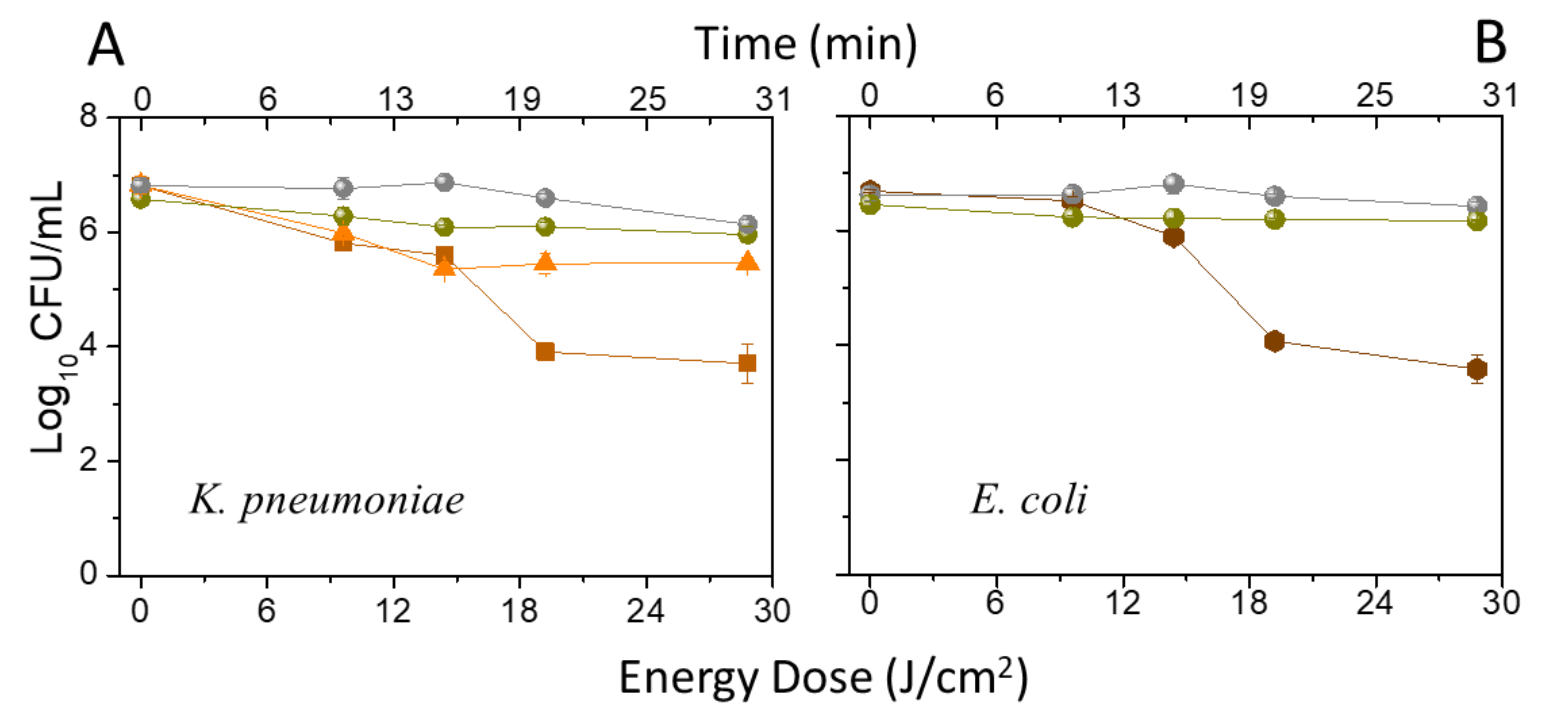

Figure S3. PDI treatment effect evaluated by measuring viable bacterial concentration as a function of irradiation time in planktonic cultures of Gram-negative species, $K$. pneumoniae and E. coli. A, K. pneumoniae culture + CPNs: $6.5 \mathrm{mg} / \mathrm{L}$ (dark orange square); $0.6 \mathrm{mg} / \mathrm{L}$ (orange triangle). Bacterial control without CPNs (dark yellow sphere) and bacterial control with CPNs $(6.5 \mathrm{mg} / \mathrm{L}$ ) but without irradiation (grey sphere). B, E. coli + light + CPNs: $16.5 \mathrm{mg} / \mathrm{L}$ (brown circle). Bacterial control without CPNs (dark yellow sphere) and bacterial control with of CPNs $(16.5 \mathrm{mg} / \mathrm{L})$ but without irradiation (grey sphere). Average irradiance (radiant flux density) $=16$ $\mathrm{mW} / \mathrm{cm}^{2}$. 

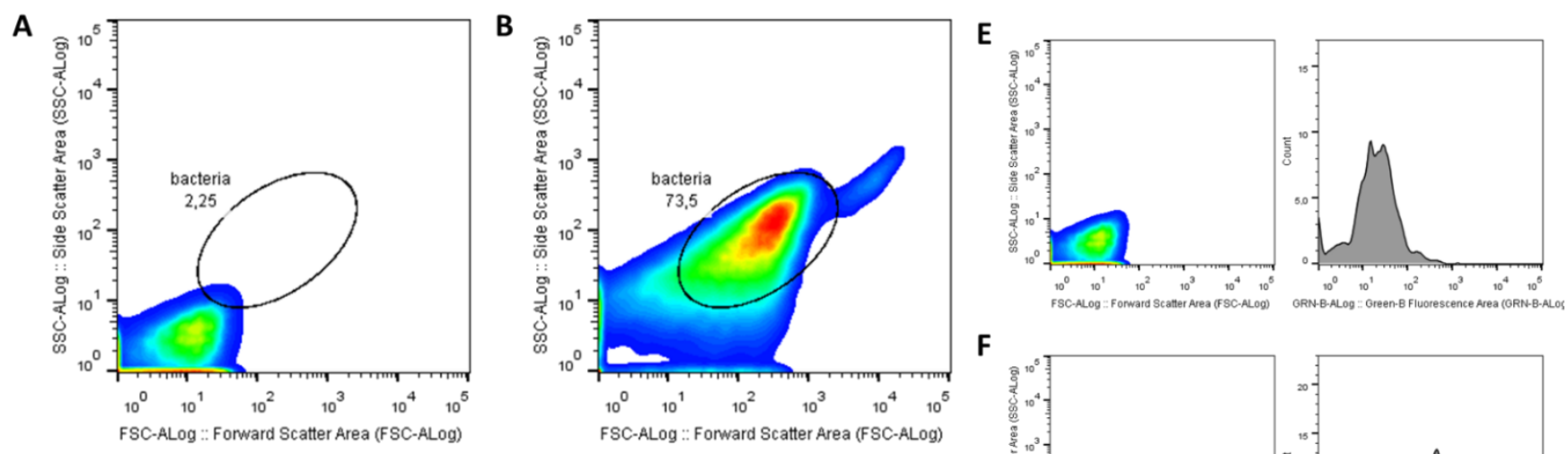

\section{F}
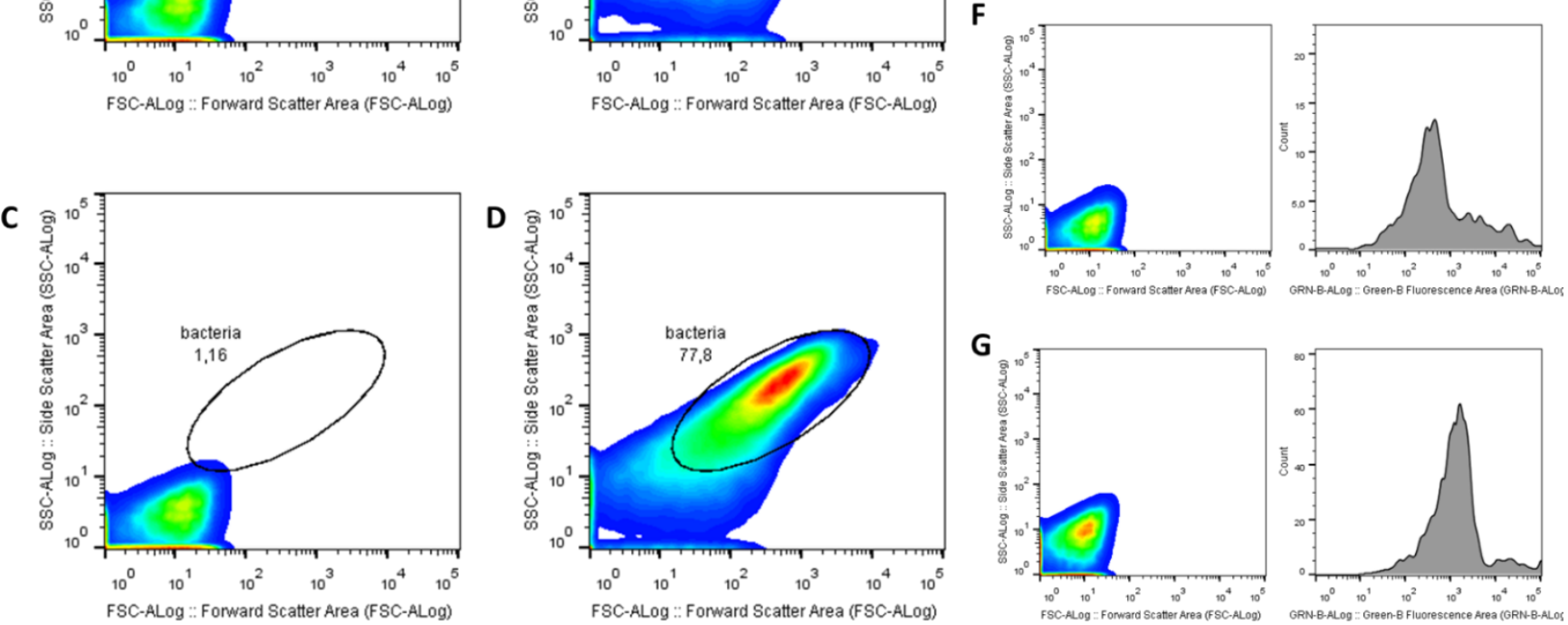

Figure S4. Flow cytometry results for CPNs and Bacteria interaction. FSC-A vs SSC-A dot plots ( $10^{5}$ total events converted to a dot density color scale) corresponding to: buffer media without bacteria (A, C) and with $10^{6} \mathrm{CFU} / \mathrm{mL}$ of E. coli (B) and S. aureus (D). The arbitrary gate region (black ellipsoid) chosen for each bacterial sample is also shown in the corresponding buffer control. The percentage values of total events within each gate region are shown next to it. FSCA vs SSC-A dot plots and corresponding green channel $\left(\lambda_{\mathrm{ex}}=488 \mathrm{~nm} \lambda_{\mathrm{em}}=525-530 \mathrm{~nm}\right)$ fluorescence histograms of 0.1 (E) $1.0(\mathrm{~F})$ and 10.0 (G) mg/L CPNs dispersion in PBS. 

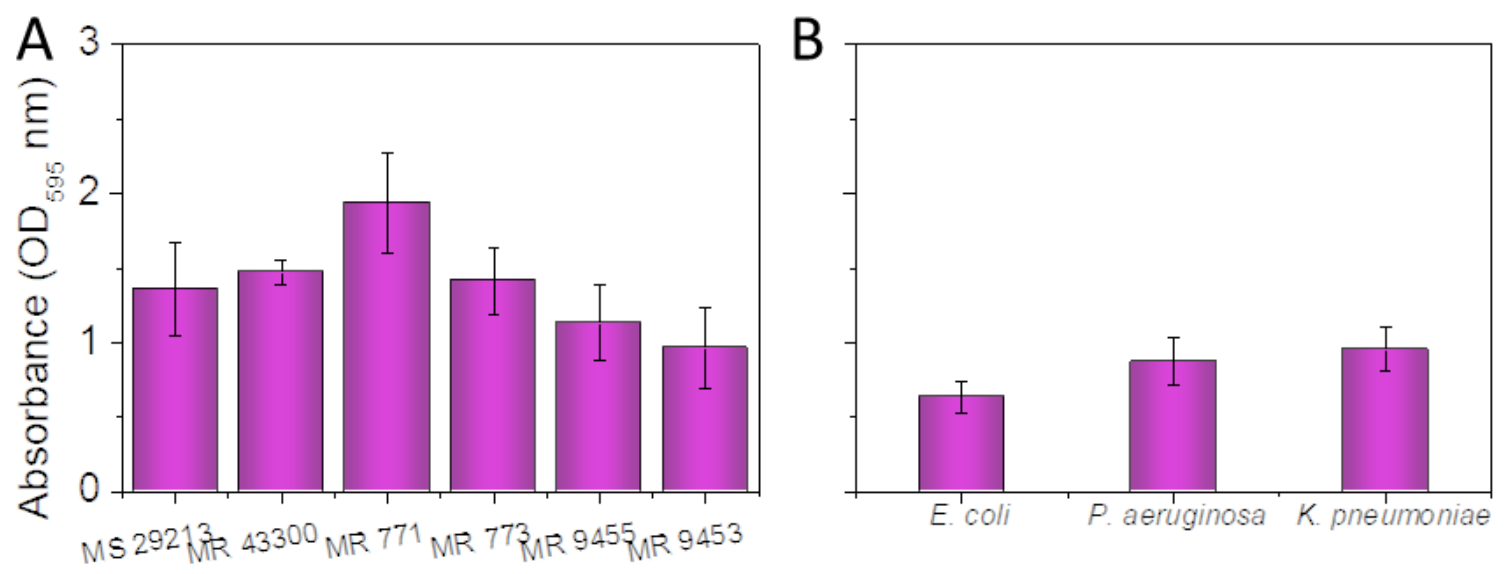

Figure S5. Relative biofilm biomass quantification as determined by the CV staining assay. Panel A) shows Gram-positive $S$. aureus strains biomass production after $24 \mathrm{~h}$ of biofilm formation. Panel B) shows biofilm biomass quantification in Gram-negative samples. 

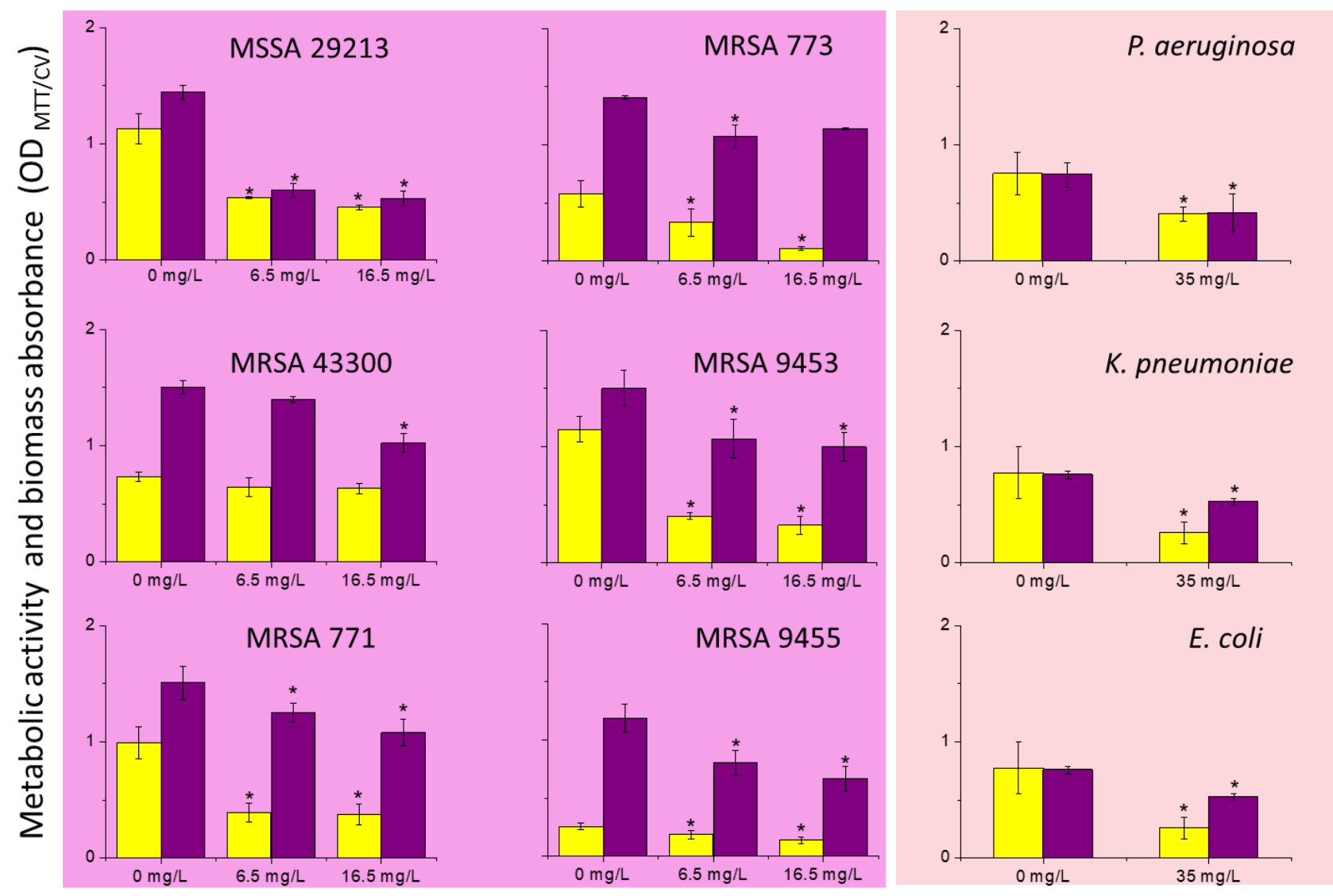

Figure S6. Biofilm biomass and metabolic activity measured by CV (purple bars) and MTT (yellow bars) colorimetric assays, respectively. The violet box on the left displays the Grampositive $S$. aureus strains whereas the pink box on the right groups the Gram-negative $P$. aeruginosa, K. pneumoniae and $E$. coli. The plots show from left to right: bacteria + light; bacteria + light + CPNs (6.5 and $16.5 \mathrm{mg} / \mathrm{L})$; and in the case of negative species with a $35 \mathrm{mg} / \mathrm{L}$ of CPNs. Biofilms samples were exposed to a light dose of $57.6 \mathrm{~J} / \mathrm{cm}^{2}\left(16 \mathrm{~mW} / \mathrm{cm}^{2}\right.$ for $\left.60 \mathrm{~min}\right)$. * p-value $<0.005$. 

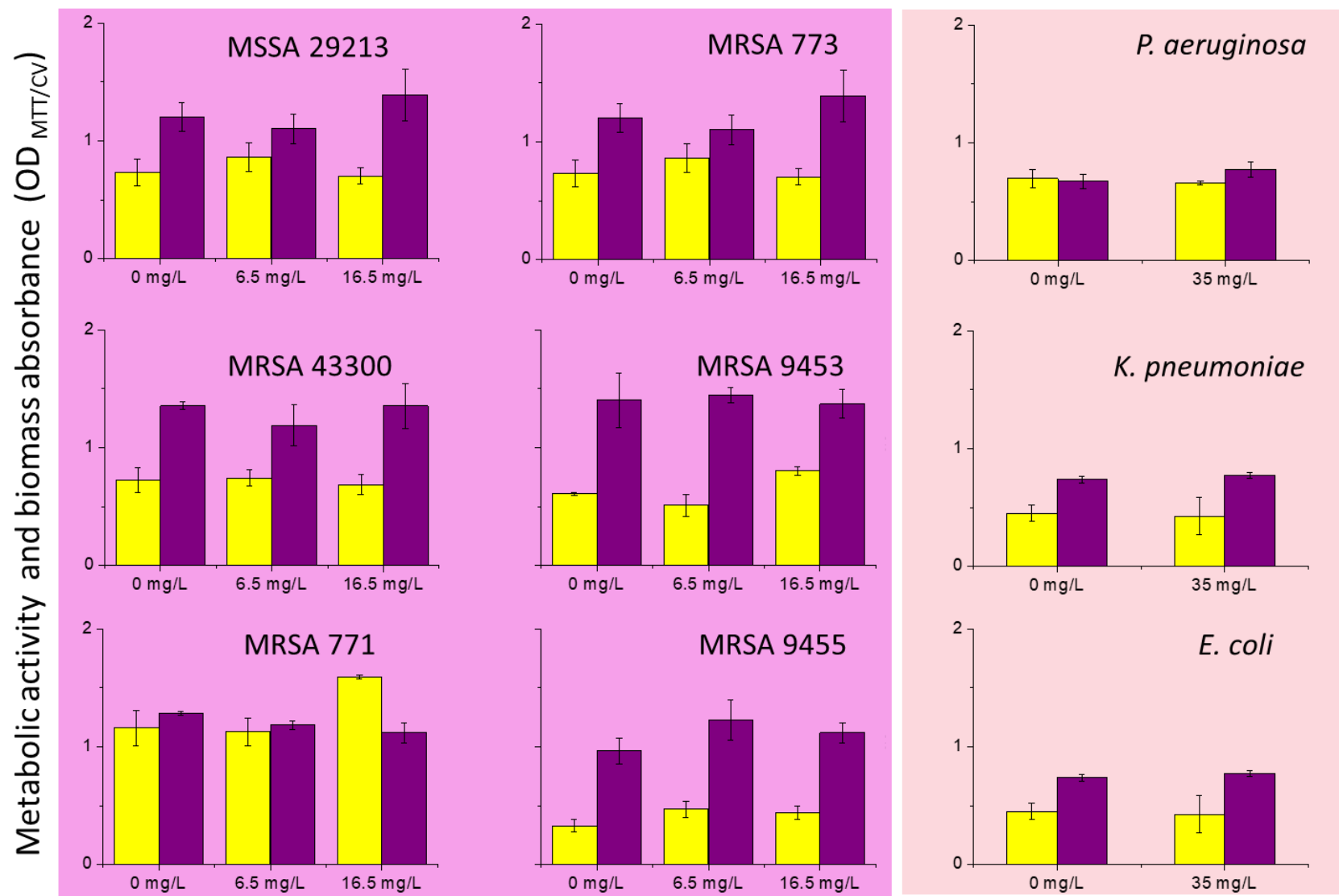

Figure S7. Biofilm biomass and metabolic activity measured by CV (purple bars) and MTT (yellow bars) colorimetric assays, respectively. The violet box on the left displays the Grampositive $S$. aureus strains whereas the pink box on the right groups the Gram-negative $P$. aeruginosa, $K$. pneumoniae and $E$. coli. The plots show from left to right: bacteria; bacteria + CPNs (6.5 and $16.5 \mathrm{mg} / \mathrm{L})$; and in the case of negative species with a $35 \mathrm{mg} / \mathrm{L}$ of CPNs. All experiments were performed in the dark. * p-value $<0.005$. 


\section{SUPPORTING REFERENCES}

1. Wu, C.; Schneider, T.; Zeigler, M.; Yu, J.; Schiro, P. G.; Burnham, D. R.; McNeill, J. D.; Chiu, D. T., Bioconjugation of ultrabright semiconducting polymer dots for specific cellular targeting. J. Am. Chem. Soc. 2010, 132, 15410-15417.

2. Ibarra, L. E.; Porcal, G. V.; Macor, L. P.; Ponzio, R. A.; Spada, R. M.; Lorente, C.; Chesta, C. A.; Rivarola, V. A.; Palacios, R. E., Metallated porphyrin-doped conjugated polymer nanoparticles for efficient photodynamic therapy of brain and colorectal tumor cells. Nanomedicine. 2018, 13, 605-624. DOI: 10.2217/nnm-2017-0292.

3. Graham, R. L.; Lubachevsky, B. D.; Nurmela, K. J.; Östergård, P. R. Dense packings of congruent circles in a circle. Discrete Mathematics. 1998, 181, 139-154.

4. $\quad$ Monteiro, J. M.; Fernandes, P. B.; Vaz, F.; Pereira, A. R.; Tavares, A. C.; Ferreira, M. T.; Pereira, P. M.; Veiga, H.; Kuru, E.; VanNieuwenhze, M. S. Cell shape dynamics during the staphylococcal cell cycle. Nat. Comm. 2015, 6, 1-12.

5. Spada, R. M.; Macor, L. P.; Hernández, L. I.; Ponzio, R. A.; Ibarra, L. E.; Lorente, C.; Chesta, C. A.; Palacios, R. E., Amplified singlet oxygen generation in metallated-porphyrin doped conjugated polymer nanoparticles. Dye Pigment. 2018, 149, 212-223.

6. Reshes, G.; Vanounou, S.; Fishov, I.; Feingold, M. Cell shape dynamics in Escherichia coli. Biophysical. 2008, 94, 251-264. 